\title{
The Innate Facet of the Brain: Human Neurons Express TLR3 and Sense Viral dsRNA
}

\author{
Monique Lafon • Françoise Megret • Mireille Lafage • \\ Christophe Prehaud
}

Published online: 7 September 2007

(C) Humana Press Inc. 2007

The credit line "Reprinted from Prehaud et al, JVI 79:12893, 2005 with permission" was mistakenly omitted from the legend of Fig. 1 and the footnote of Table 1. Thus Fig. 1 and Table 1 are hereby replaced with the following figure and legend:
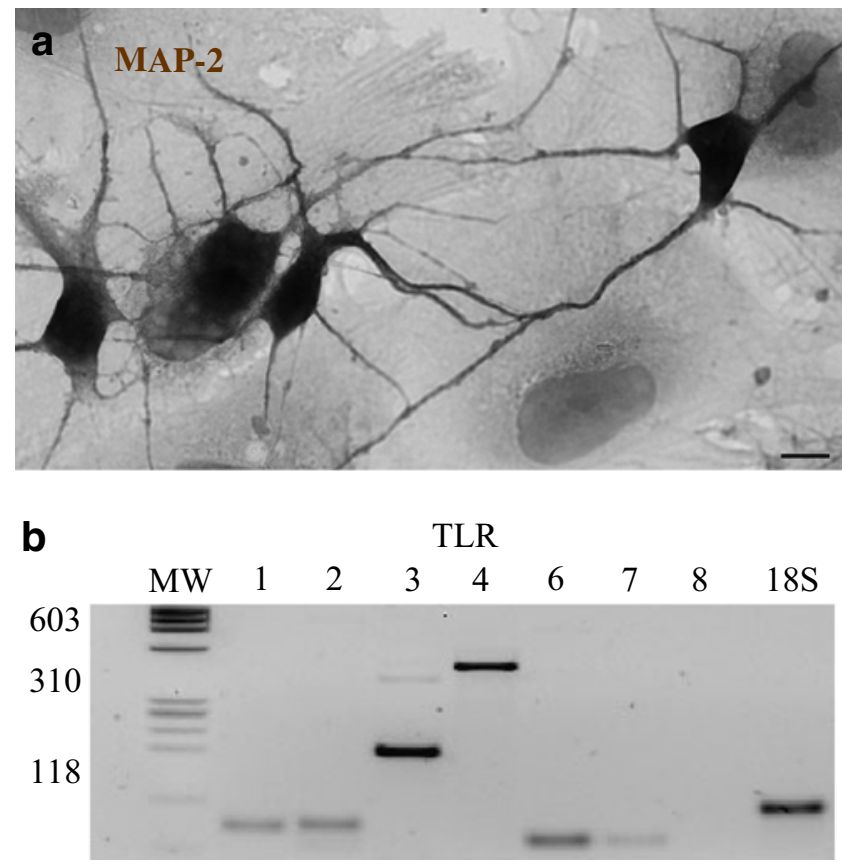

Figure 1 NT2-N cultures are pure human post-mitotic neuron preparations susceptible to RABV and HSV-1 infection. a) Immunocytochemistry : NT2-N cells express MAP-2 in their cellular bodies and dendrites. They express the high molecular weight neurofilament (NeuF-H) and in contrast to normal human brain, they do not express MOG or GFAP markers of oligodendrocytes or astrocytes respectively (Prehaud et al. 2005). They do not express CD200R either, (Prehaud et al. 2005) a marker of microglia, here the human microglial cell line, CHME (Janabi et al. 1995). Bars on the photograph represent $10 \mu \mathrm{m}$. b) RT-PCR analysis showed that NT2-N express transcripts of TLR1,

The online version of the original article can be found at http://dx.doi. 2, 3, 4, 6 and 7. TLR5 and 8 were not detected. TLR9 was not tested. org/10.1385/JMN/29:03:185 $18 \mathrm{~S}$ was used as an housekeeping gene. $\mathrm{MW}=$ molecular weights

M. Lafon $(\bowtie) \cdot$ F. Megret $\cdot$ M. Lafage $\cdot$ C. Prehaud Unité de Neuroimmunologie Virale, Department of Neuroscience, Institut Pasteur,

75724 Paris, France

e-mail: mlafon@pasteur.fr

Also, the credit line "Implemented from data from Prehaud et al, JVI 2005" was omitted in the footnote to Table 2 and legend of Fig. 4. 